first, ${ }^{1}$ they referred to the "in situ left internal thoracic artery." The term in situ is a Latin phrase meaning "in position." In their article, they said that the internal thoracic artery was divided and then the 2 ends were swung on pedicles to anastomose with 2 coronary sites. Because parts of the arterial segments were moved from their original position, they were no longer in situ, and the authors' use of this terminology is therefore incorrect. A more consistent description would refer to both conduits as pedicled, nonskeletonized, and based on proximal and distal pedicles for their blood supply.

The same error related to the incorrect use of the term in situ appears to have occurred in the second article from Dr Nezic's group. ${ }^{2}$ On examination of the diagram, it would appear that the conduit was a pedicled nonskeletonized internal thoracic artery that was based on a distal pedicle as the blood supply. We would not refer to the described conduit as free because it was left attached to its original circulatory connection, although unusually in this case the connection was distal.

We are unable to comment on the third quoted article because it is in press at our writing.

We thank Dr Nezik for drawing attention to the ongoing confusion that can plague surgical communications, and we hope that these conversations will highlight the need for standardization and strict editorial attention in our journals.

Hadi Toeg, MD

Fraser Rubens, MD, MSc, FACS, FRCSC

University of Ottawa Heart Institute Ottawa, Ontario, Canada

\footnotetext{
References

1. Nezic D, Antonic Z, Knezevic A, Bojovic Z. Split, in situ left internal thoracic artery to revascularize left anterior descending coronary artery system. $J$ Thorac Cardiovasc Surg. 2011;142:1579-80.
}

2. Nezic D, Antonic Z, Bojovic Z, Milicic M, Boricic M, Kecmanovic V, et al. How to use the left internal thoracic artery which has been damaged during harvesting? Ann Thorac Surg. 2012;94:269-71.

http://dx.doi.org/10.1016/ j.jtcvs.2013.12.027

\section{A LOT OF DRUGS AND NOT MUCH OXYGEN: IS THE COCKTAIL RESPONSIBLE FOR DELIRIUM?}

\section{To the Editor:}

We read with great interest the article by Arenson and colleagues ${ }^{1}$ that analyzed the risk factors for postoperative delirium, with particular reference to the influence of intensive care unit environment, in a large study population undergoing cardiac surgery. In their multivariate analysis, postoperative delirium was significantly associated with preoperative (eg, age, preadmission use of benzodiazepine), intraoperative (eg, combined coronary artery bypass grafting and valve surgery), and postoperative (eg, stroke or transient ischemic attack, mechanical ventilation $>24$ hours, blood transfusion, postoperative renal insufficiency) risk factors. These findings confirm the multifactorial triggers and causes of this neurologic complication and may contribute to its prevention and better management of this phenomenon. In particular, Arenson and colleagues ${ }^{1}$ found an influence of intensive care environment in patients younger than 65 years. We agree with Inouye ${ }^{2}$ that a substantial proportion of delirium is preventable through appropriate care and attention. In a study of our group that used near-infrared spectroscopy for cerebral saturation monitoring, a higher incidence of postoperative delirium was observed in patients with a bispectral index reduction more than $25 \%$ from baseline. ${ }^{3}$

Near-infrared spectroscopy is routinely used in many centers as a monitor for depth of anesthesia. Regardless of the causes of cerebral oxygen desaturation (excessive anesthetic depth, bypass flow set too low, inadequate selective cerebral perfusion), near-infrared spectroscopy allows detection of periods of decreased oxygen delivery to the brain or of critical thresholds of oxygen delivery and can help predict postoperative stroke and delirium or cerebral ischemia. ${ }^{3}$ Our study was aimed at evaluating alternatives for improving the outcomes of this patient subset. The detection of reduced cerebral oxygen saturation during surgery may change the management of these patients, leading to the development of specific treatment protocols (eg, prolonged weaning with presence of family members, delayed mobilization, differentiated analgesia). As hypothesized by Martin and coworkers, ${ }^{4}$ delirium may be related to changes in the blood-brain barrier that occur in response to systemic inflammation after cardiopulmonary bypass, even though reduced risks were not observed in patients undergoing off-pump bypass surgery. We strongly believe that the integrity of the blood-brain barrier may be compromised as a result of paradoxic pharmacologic effects: in common clinical practice, delirious patients often receive a wide range of active compounds targeting different receptors (analgesics, sedatives, antipsychotics) during both the diurnal and nocturnal periods. A disrupted bloodbrain barrier can allow drugs to enter the brain in variable quantities. Because of pharmacologic interactions not yet fully understood, in particular those related to the use of benzodiazepines, such a drug cocktail may have the paradoxic effect of worsening the delirium. ${ }^{5}$ This interpretation is compatible with findings of Arenson and colleagues ${ }^{1}$ and motivates an attention to preventive measures. Our contribution aims to add value to the debate regarding delirium prevention and management: the use of near-infrared spectroscopy, the implementation of 
strategies other than pharmacologic treatment, or the use of other drugs of the same class with predominantly analgesic effects not affecting brain receptors (eg, morphine derivatives) may induce the surgeon to refrain from administering a life-threatening drug cocktail that may be responsible for triggering or worsening delirium.

Francesco Pollari, MD

Giuseppe Santarpino, MD

Theodor Fischlein, MD

Department of Cardiac Surgery

Klinikum Nürnberg

Nuremberg, Germany

\section{References}

1. Arenson BG, MacDonald LA, Grocott HP, Hiebert BM, Arora RC. Effect of intensive care unit environment on in-hospital delirium after cardiac surgery. J Thorac Cardiovasc Surg. 2013;146:172-8.

2. Inouye SK. Delirium in older persons. $N$ Engl $J$ Med. 2006;354:1157-65. Erratum in: N Engl J Med. 2006:354:1655.

3. Santarpino G, Fasol R, Sirch J, Ackermann B, Pfeiffer S, Fischlein T. Impact of bispectral index monitoring on postoperative delirium in patients undergoing aortic surgery. HSR Proc Intensive Care Cardiovasc Anesth. 2011;3:47-58.

4. Martin BJ, Buth KJ, Arora RC, Baskett RJ Delirium: a cause for concern beyond the immediate postoperative period. Ann Thorac Surg. 2012;93:1114-20.

5. Zeller A, Crestani F, Camenisch I, Iwasato T, Itohara S, Fritschy JM, et al. Cortical glutamatergic neurons mediate the motor sedative action of diazepam. Mol Pharmacol. 2008;73:282-91.

\section{http://dx.doi.org/10.1016/} j.jtcvs.2013.09.079

\section{Reply to the Editor:}

We are appreciative and in agreement with the point of view that Pollari and colleagues have expressed regarding our study outlining some of the risk factors for postoperative delirium after cardiac surgery. One of the messages inherent in our observational study is that certain potentially modifiable factors can, if appropriately commented on the study by Santarpino and colleagues examining the effect of cerebral monitoring as a method of identifying patients who might have a greater incidence of delirium. Although it is exciting that the use of a cerebral monitor might represent a clinically available biomarker, the data supporting the use of processed electroencephalographic monitoring (eg, the bispectral index and nearinfrared spectroscopy cerebral oximetry) are quite sparse. Importantly, their report appears to have confused nearinfrared spectroscopy and processed electroencephalographic monitoring. Thus, although we are appreciative of their interest in our report, their points regarding near-infrared spectroscopy would be much better supported by a study that had not used a processed electroencephalography (bispectral index) to estimate the cerebral saturation. Finally, we do agree with the authors that a focus on preventative measures is a necessary direction of future research in addressing delirium in the postoperative cardiac surgery patient.

Benjamin G. Arenson, $B S c^{a}$ Lindsey A. MacDonald, BSc ${ }^{b}$ Hilary P. Grocott, MD, FRCPC ${ }^{a}$ Brett M. Hiebert, $M S c^{c}$ Rakesh C. Arora, MD, PhD, FRCSC ${ }^{d}$

${ }^{a}$ Department of Anesthesia and Perioperative Medicine

${ }^{b}$ University of Manitoba Faculty of Medicine

Winnipeg, Manitoba, Canada

${ }^{c}$ Cardiac Sciences Program

Winnipeg Regional Health Authority Winnipeg, Manitoba, Canada

${ }^{d}$ Departments of Anesthesia and Perioperative Medicine and Surgery University of Manitoba Faculty of Medicine

Winnipeg, Manitoba, Canada

http://dx.doi.org/10.1016/ j.jtcvs.2013.11.059

\section{THE EFFECTS OF BICUSPID}

\section{AORTA}

To the Editor:

Congratulations to Katayama and colleagues $^{1}$ for this study showing that tricuspid valves are superior in the aortic position. The diameter of the aorta increases $10 \%$ in systole relative to diastole. Tricuspid aortic leaflets do not resist this increase, but bicuspid aortic leaflets do resist because of their position. Bicuspid aortic leaflets thus undergo trauma during systole. In addition, tricuspid aortic leaflets get closer to the aortic wall during systole than do bicuspid ones. This causes bicuspid aortic leaflets to be exposed to more friction and shear stress. Twisting of the ascending aorta laterally and dorsally and localization of the coaptation line of bicuspid leaflets, however, were ignored in this simulation. The differences in the characteristics will influence the flow patterns. Configuration of the aortic valve and ascending aorta should therefore be considered in the simulation.

The noncoronary wall has the highest $\mathrm{dp} / \mathrm{dt}$ in the ascending aorta. Therefore, in people with normal (tricuspid) aortic valves, the longest free edge is that of the noncoronary leaflet. Ninety-five percent of aortic dissections start from the wall of the noncoronary cusp. One of the most important factors affecting the surgical success of repair of bicuspid aorta is the localization of the commissure on the annulus. The localization of the commissures at the anteroposterior position on the annulus would increase surgical success. In this position, the noncoronary wall of the aorta would be less influenced by the $\mathrm{dp} / \mathrm{dt}$ ratio. We think that the anatomic positions of the commissures on the annulus should be taken into consideration in this study.

Habib Cakir, MD

Mert Kestelli

Ismail Yurekli, MD

Koksal Donmez, $M D$

Department of Cardiovascular Surgery

Katip Celebi University Izmir Atatürk

Training and Research Hospital Izmir, Turkey 